\title{
Use of a Combination of AHP and ISM for Making an Innovative Rescue Caring Design in Landslide Area
}

\author{
Ming-Tang Wang \\ Department of Industrial Design, National Kaohsiung Normal University, Kaohsiung 824, Taiwan \\ Correspondence should be addressed to Ming-Tang Wang; mtwang2000@gmail.com
}

Received 4 October 2014; Accepted 12 December 2014

Academic Editor: Mo Li

Copyright (C) 2015 Ming-Tang Wang. This is an open access article distributed under the Creative Commons Attribution License, which permits unrestricted use, distribution, and reproduction in any medium, provided the original work is properly cited.

\begin{abstract}
A design concept is proposed for using a combination of two types of decision-making models to determine the design direction. Based on research processes, it is conducted to solve rescue related issues in harsh terrain or landslides, which can often be attributed to the global climate becoming unstable, increasing the frequency of mudflows and landslides, therefore creating more emergencies of this type. ATV vehicles are advantageous for such disasters. In order to discover the needs for ATV's carrying abilities, five rescue experts were interviewed and three additional experts participated in the AHP process. A stretcher was determined to be the first priority to be mounted on an ATV. Nine higher score items were selected to create a stretcher mechanism from a questionnaire survey in VOA. ISM recognized the main target, with the intention to solve the safety problems (level 2) and the usability issues (level 3) of the proposed stretcher. Finally, a new stretcher structure was designed with a spinal board to be safe and detachable for conveying patients. The stretcher body can also be folded and hung up for easy transporting and even combined with the trunk pack which contains various breathing assistance equipment.
\end{abstract}

\section{Introduction}

Taiwan is located on the border of the Eurasia and Philippine plates; Eurasian plate is still moving $7 \sim 8 \mathrm{~cm}$ to the northwest direction every year [1]. Owing to the fact that the junction of the plate has such significant movement, it became a mountainous region with steep terrains, outcroppings, and generally young and fragile lithology. Also due to the plate's movements, natural disasters are a high risk, such as earthquakes, typhoons, floods, and surface deformation. The growing economy leads to excessively exploited mountain regions, which in turn often causes loss of life and property when a typhoon brings heavy rain, causing seasonal floods, landslides, and mudslides.

This leads one to consider suitable methods to convey patients when landslides cause injuries to people. Many policy makers and scholars have paid special attention to the relationship between man and nature. Therefore, we need to propose an innovative and thoughtful design in order to rescue emergency patients in mountain landslides and other natural disasters.
In this study, researchers are trying to add thoughtful concepts in product designs as a new method of thinking, by researching awareness literature in industrial design and proposing nature-friendly designs. Designing in this way is conceiving, planning, and presenting a creative action with a target. This developing process is a series of conversion activities, transferring imagination and ideas into a real product. The general developing process of a product includes at least 6 steps, which are planning, concept development, system-level design, detail design, testing and refinement, and production ramp-up [2], which can be constructed in 4 stages, planning, designing, prototyping, and engineering [3]. The implications for design were profound; manufacturers found that a designer could add value for a product; the stylist could make a product more appealing and more likely to be purchased [4]. Designers became more interested in producing "want" products rather than "need" products, because they can create desire [5]. Consumers always advocate usercentered needs, so the design could not yet be described as being "consumer-led." Rather, the manufacturers determined what should be produced [4]. The mismatch was felt by this 
design, and the lack of moral responsibility was evident to the design profession [6]. Consumer products have become the equivalent of boom indicators, and, in the meantime, product design has merely become a tool of capitalism.

Can producing a product design from a tool image in a "caring" way be seen as spiritual? Caring is a state of mental suffering or of engrossment: to care is to be in a burdened mental state, one of anxiety, fear, or solicitude about something or someone. Alternatively, one cares for something or someone if one has a regard or inclination towards that something or someone [7]; "caring" is also defined as being kind and helpful and showing that you are concerned about other people in the oxford dictionary [8]; it is a real knowledge which comes from our lives and manifests itself in love towards people. Caring is one of the most profound feelings and is rooted in acceptance and response [9]. Many scholars pointed out that behavior like doing well to others or helping others lays on the foundation of altruism $[10,11]$. Establishing the rationality of care design can be enhanced by promoting the application of this design concept in design education. If the relationship between people and product design is established, the applications chance will be developed [12-14]. Therefore, the caring concept can become tacit knowledge from people and can be used to eliminate the gap for a better design development: which process of product design can be filled with extraordinary ideas, determining a more clear resolution for design.

1.1. Product Design for Caring User. Because there are few designs discussed with care in mind, something like mobile phone development and design becomes an example of this issue. In particular, the hearing impaired persons are greatly disadvantaged by cell phone design [15]; thus research is continuing to improve these devices, mainly for senior citizens [12]. The disaster of the Wenchuan earthquake in mainland China brought to the surface new ideas for caring rescue systems: additional functions of new designs with concerns for the victims [16]. And a study is even being done for female consumers, searching for meaningful designs that still contain the caring element [17].

1.2. Analytic Hierarchy Process (AHP). Since the analytic hierarchy process (AHP) was developed by [18], a systems analysis technique for solving decision problems, there has been a wide discussion about the empirical effectiveness and theoretical validity of the technique [18-21]. The methodology of the AHP is basically to transform a complex decision problem into elemental issues (i.e., clustering) to create a hierarchical model. For a typical hierarchy, the overall goal (usually the selection of the best alternatives) is situated at the highest level; elements with similar nature are grouped at the same interim level(s) and decision variables (usually alternatives) are situated at the lowest level [22]. Structural evaluation is a systematic determination of merit, worth, and significance of something using criteria against standards. This involves human perceptual interpretation with some uncertainty and imprecision. It discusses a basic principle in the AHP that valid results depend on establishing priorities for the criteria and priorities for the alternatives with respect to each criterion and synthesizing the results by weighing and adding. The AHP consists of three main operations, namely, hierarchy construction, priority analysis, and consistency verification, and accurate expression of the relative preferences on the criteria is limited on Saaty's discrete 9 segments of the Likert scale $[23,24]$. This paper focuses instead on the priorities among alternatives.

This method process is also popular in practical projects. It was determined that the priorities in technological development for energy efficiency and greenhouse gas control plans (EGCP) are part of a new national energy and resource technology R\&D plan (NERP) in Korea, by using the AHP approach for the first time [25]. At least two approaches can be identified for such applications. In the first approach, the AHP priorities are used as coefficients in the objective function of the LP format, and, in the second approach, the benefit-cost ratios are used as the coefficients [26]. Generally, customer lifetime value (CLV) is evaluated in terms of recentness, frequency, and monetary (RFM) variables. However, the relative importance among them varies with the characteristics of the product and industry. We developed a novel product recommendation methodology that combined group decision-making and data mining techniques. The analytic hierarchy process (AHP) was applied to determine the relative weights of RFM variables in evaluating customer lifetime value or loyalty [27]. To develop a decision support system, we used the fuzzy sets theory being integrated with AHP (analytical hierarchy process) for locating a new appropriate convenience store [28]. The paired comparisons are used to weigh the importance of attributes based on a hierarchical structure and the things required that decision makers use to remain consistent in making pairwise comparisons among numerous decision criteria [29]. It developed a convenient and effective eigenvalue algorithm for deriving the weights of criteria for UD (universal design) [30], constructing the customer requirement impact factors of the baby walker based on orange technology, in order to create a smarter living space. During questionnaires and interviews conducted by expert researchers in combination with the fuzzy Delphi method, the analytical hierarchy process method was used for the weight value calculation of these criteria [31].

1.3. Process of Interpretive Structural Modeling (ISM). People usually judge based on their intuition and experiences when they study complex, divisive issues, conduct problem analysis, and make assessments. Interpretive structural modeling (ISM) is used for ideal planning, which is an effective method because all elements can be processed within a simple matrix. ISM was proposed and developed by Warfield from 1973 [3236]; it is also a well-established methodology for identifying relationships among specific items, which defines a problem or an issue $[37,38]$, and a suitable modeling technique for analyzing the influence of one variable on other variables [39], often used to provide a fundamental understanding of complex situations, and putting together a course of action for solving a problem. Its mathematical foundations of the methodology can be found in various reference works [40]. 


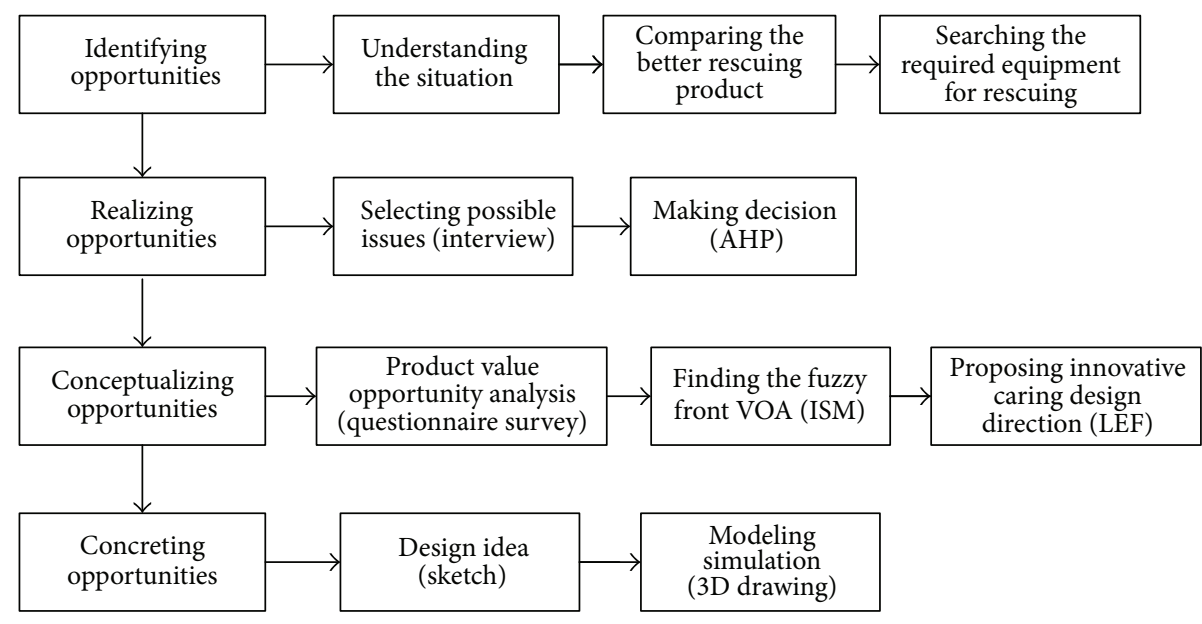

FIGURE 1: The procedure and main method of this study.

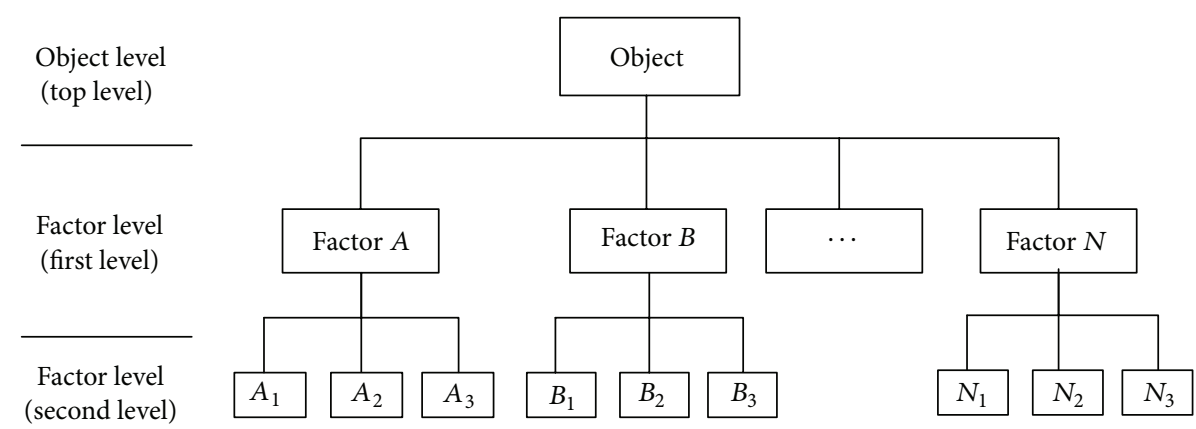

FIGURE 2: The structure of AHP.

ISM can be used to help groups of people in structuring their collective knowledge [41]; its systematic application of graph theory in a way that uses theoretical, conceptual, and computational leverage is applied to efficiently construct a directed graph for referencing $[41,42]$. Some design planning [43-45] and productivity issues [46] have provided sufficient ground to begin with ISM research.

\section{Methodology}

This study starts with a qualitative survey and follows with a verified quantitative survey in relation to the process of caring design, which is divided into four stages: "identifying opportunities," "realizing opportunities," "conceptualizing opportunities," and "concreting opportunities." Figure 1 shows that every stage has process with professional methods to solve or decide doubt or still uncompleted points.

2.1. Identifying Opportunities. Researching mountainous rescue products depend on (1) understanding the rescue vehicles, (2) choosing the better rescue vehicle for special terrain, and (3) selecting the required equipment.

2.2. Realizing Opportunities: Discussing Suitable Products for Rescuing. Realizing opportunity is to induct a design direction, by (1) selecting possible issues by interviewing experienced rescue experts and (2) operating analytic hierarchy processes (AHP) with software programs. The AHP proposed system consists of four main components of the process as follows.

(1) Hierarchical structure development of the AHP (Figure 2): this is to review the related papers and interview the experts about the specific domain to decompose the problem hierarchically.

(2) Weights determination: AHP $n$ elements are compared, $C_{1} \cdots C_{n}$, and denote the relative "weight" (or priority or significance) of $C_{j}$ with respect to $C_{j}$ by $a_{i j}$ and form a square matrix $A=\left(a_{i j}\right)$ (formula (1)) of order $n$ with the constraints that $1 / a_{i j}=1 / a_{j i}$ for $i \neq j$ and $a_{i i}=1$, all $i(1,2,3, \ldots, n)$. Such a matrix is said to be a reciprocal matrix 
TABLE 1: Issues in product value opportunities analysis $[49,50]$.

\begin{tabular}{|c|c|c|}
\hline Category & Item & Description \\
\hline \multirow{6}{*}{ Emotion } & Courage & Rescuers can be inspired when they use a suitable product. \\
\hline & Independence security & Rescuers can operate independently and the equipment has the versatility on other tasks. \\
\hline & & Rescuers can feel safe. \\
\hline & Sensibility & The equipment can make rescuers feel confident in themselves. \\
\hline & Confidence & Ease of use of equipment increases rescuers' confidence. \\
\hline & Power & Rescuers can handle situations by using equipment. \\
\hline \multirow{3}{*}{$\begin{array}{l}\text { Human factors } \\
\text { engineering }\end{array}$} & Comfortable & Feeling comfortable with no pressure when using rescuing equipment. \\
\hline & Safety & It is safe to use and will not put users in danger. \\
\hline & Usability & Being simple and easy to use. \\
\hline \multirow{5}{*}{ Aesthetics } & Sight & The equipment is good looking. \\
\hline & Sense of touch & Feeling smooth with no discomfort. \\
\hline & Auditory sense & Equipment does not make noises. \\
\hline & Nose & The material has no peculiar smell. \\
\hline & Sense of taste & Being not harmful or uncomfortable to mouth. \\
\hline \multirow{2}{*}{ Image } & Time & Ability to meet the time or frequency when local disaster happens. \\
\hline & Location & Being fit for local rescuing demand. \\
\hline \multirow{2}{*}{ Influence } & Society & Having adaptable equipment to fit various environments and situations. \\
\hline & Environment & Not having any harmful influence to environment. \\
\hline \multirow{2}{*}{ Core technology } & Reliability & Product can use stable without trouble. \\
\hline & Availability & The core tech. must meet the product's function and be easily accessible when needed. \\
\hline \multirow{2}{*}{ Quality } & Craft & The product must have high quality. \\
\hline & Durability & The product must achieve the high durability. \\
\hline
\end{tabular}

[47]. The main goal of the questionnaire is to compare pairs of elements, or criteria, of each level with respect to every element in the higher level. In [48], a nine-segment scale is recommended, integrating from different experts' opinions:

$$
\begin{gathered}
A=\left[a_{i j}\right]_{n \times n}=\left[\begin{array}{cccc}
1 & a_{12} & \cdots & a_{12} \\
\frac{1}{a_{12}} & 1 & \cdots & a_{n 2} \\
\vdots & \vdots & \ddots & \vdots \\
\frac{1}{a_{1 n}} & \frac{1}{a_{2 n}} & \cdots & 1
\end{array}\right], \\
=\left[\begin{array}{cccc}
\frac{W_{1}}{W_{1}} & \frac{W_{1}}{W_{1}} & \cdots & \frac{W_{1}}{W_{n}} \\
\frac{W_{2}}{W_{1}} & \frac{W_{2}}{W_{2}} & \cdots & \frac{W_{2}}{W_{n}} \\
\vdots & \vdots & \ddots & \vdots \\
\frac{W_{n}}{W_{1}} & \frac{W_{n}}{W_{2}} & \cdots & \frac{W_{n}}{n}
\end{array}\right] . \\
a_{i j}=\frac{W_{I}}{W_{J}}, \quad a_{i j}=\frac{1}{a_{j i}} \\
i, j=1,2,3, n .
\end{gathered}
$$

(3) Calculating eigenvectors and the largest eigenvalue: the weight of each factor has been determined; the corresponding data of each evaluation factor should be collected to terrain. The weights are consistent if they are transitive; that is, $a_{i k}=a_{i j} a_{j k}$ for all $i, j$, and $k$. Such a matrix might exist if the $a_{i j}$ are calculated from exactly measured data. Then find a vector $\omega$ of order $n$ such that $A_{\omega}=\lambda_{\omega}((2))$. For such a matrix, $\omega$ is said to be an eigenvector (of order $n$ ) and $\lambda$ is an eigenvalue. For a consistent matrix $\lambda=n$ for matrices involving human judgment, the condition $a_{i k}=a_{i j} a_{j k}$ does not hold as human judgments are inconsistent to a greater or lesser degree. In such a case the $\omega$ vector satisfies the formulas $A_{\omega}=\lambda_{\max \omega}$ and $\lambda_{\max } \geq n$. The difference, if any, between $\lambda_{\max }$ and $n$ is an indication of the inconsistency of the judgments. If $\lambda_{\max }=n$ then the judgments have turned out to be consistent:

$$
A_{\omega}=\frac{\left[\prod_{i=1}^{n} a_{i j}\right]}{\sum_{1}^{n}\left[\prod_{i=1}^{n} a_{i j}\right]^{1 / n}} ; \quad i, j=1,2,3, \ldots, n
$$

The largest eigenvalue: First a pairwise comparison of matrix $A$ is multiplied by the eigenvectors $W_{1}$, getting a new 
TABle 2: The comparisons of possible rescue carriers.

\begin{tabular}{|c|c|c|c|c|c|c|}
\hline \multirow{2}{*}{ Item } & \multirow{2}{*}{\multicolumn{3}{|c|}{ Helicopter/S70-C }} & \multicolumn{3}{|l|}{ Type 1} \\
\hline & & & & 4WD /Hummer H1 & & $\operatorname{ATV}(500 \mathrm{cc})$ \\
\hline (1) Flexibility & $\mathrm{X}$ & Only has $4.5 \mathrm{hr}$ endurance capacity. & ๑ & $\begin{array}{l}\text { Affected by road } \\
\text { conditions. }\end{array}$ & $\odot$ & $\begin{array}{l}\text { Almost not influenced } \\
\text { by road conditions }\end{array}$ \\
\hline (2) Max of loading capability & $\odot$ & $9,000 \mathrm{lb}$. & $\odot$ & $6,000 \mathrm{lb}$ & $\mathrm{O}$ & $440 \mathrm{lb}$. \\
\hline (3) Approaching disaster area & $\mathrm{X}$ & $\begin{array}{l}\text { Need appropriate space to land, and } \\
\text { only can hang or air drop. }\end{array}$ & $\bigcirc$ & $\begin{array}{l}\text { Not easy to drive on } \\
\text { mountain road collapse. }\end{array}$ & $\odot$ & $\begin{array}{l}\text { Capable of driving on } \\
\text { bad road condition. }\end{array}$ \\
\hline (4) Cost of operation & $\mathrm{X}$ & 800 thousand/time. & $\bigcirc$ & $\begin{array}{l}\text { Consumption is higher } \\
\text { than usual cars. }\end{array}$ & $\odot$ & Lower than usual cars. \\
\hline (5) Price & $\mathrm{X}$ & About $\$ 27,000,000$ & $\mathrm{O}$ & About $\$ 130,000$. & $\odot$ & About $\$ 11,000$. \\
\hline (6) Universality & $\bigcirc$ & Government agencies. & $\bigcirc$ & $\begin{array}{l}\text { In government agencies, } \\
\text { civil society groups. }\end{array}$ & $\odot$ & Civil society groups. \\
\hline
\end{tabular}

The description of mark: ๑, excellent; $\bigcirc$, good; $X$, poor.

vector $W_{1}^{\prime}$ (formula (3)), which is then averaged between multiples of $\lambda_{\max }$ (formula (4)):

$$
\begin{gathered}
{\left[\begin{array}{cccc}
1 & a_{12} & \cdots & a_{12} \\
a_{21} & 1 & \cdots & a_{n 2} \\
\vdots & \vdots & \ddots & \vdots \\
a_{n 1} & a_{n 2} & \cdots & 1
\end{array}\right]\left[\begin{array}{c}
W_{1} \\
W_{2} \\
\vdots \\
W_{N}
\end{array}\right]=\left[\begin{array}{c}
W_{1}^{\prime} \\
W_{2}^{\prime} \\
\vdots \\
W_{n}^{\prime}
\end{array}\right],} \\
\lambda_{\max }=\frac{1}{n}\left[\frac{W_{1}^{\prime}}{W_{1}}+\frac{W_{2}^{\prime}}{W_{2}}+\cdots+\frac{W_{n}^{\prime}}{W_{n}}\right] .
\end{gathered}
$$

(4) Consistency test: the pairwise comparison matrix $A$ is consistent with the consistency of the matrix, so the results of the assessment should be checked with a consistency test, in order to check the pairwise comparison matrix used by policy makers to answer whether the consistency matrix can be used properly. Saaty [18, pages 11-32] suggested that the consistency index (consistency index, C.I.) and consistency ratio (consistency ratio, C.R.) test the consistency of pairwise comparison matrices. A consistency index (C.I.) can be calculated as follows [47]:

$$
\text { C.I. }=\frac{\lambda_{\max }-n}{n-1} .
$$

While C.I. $=0$ indicates exactly same as before and after the judgment, C.I. $>0$ indicates that values before the judgment are inconsistent and C.I. $\leq 0.1$ allows comparable errors. Secondly, consistency index (C.I.) affects the size of the order of the matrix $A$ and the scale of assessments, C.I. value matrix $A$; in order to assess the number and scale of all known cases, the result is called stochastic (random index, R.I.). This value can be obtained by a look-up table (Table 6). In the same order of the matrix, the ratio of the value of C.I. and R.I. is called the consistency ratio (C.R.) (formula (6)), which is defined as follows:

$$
\text { C.R. }=\frac{\text { C.I. }}{\text { R.I. }}
$$

2.3. Conceptualizing Opportunities: Discussion of Caring Design Concept. The collection of emotional demands from interviews of professional users was used in the process of caring design. Improving shortcomings and using good points to make sure that designs become reasonable and innovative were among the priorities.

(1) Processing product value opportunity analysis measured the scale of value opportunity analysis (VOA) $[49,50]$ in questionnaires made by related experts. It was used to construct hierarchical interaction graphs of the systems and areas of the main problem and the main target design of ISM. The original design proposal can be divided into 7 different categories: emotion, human factor engineering, aesthetics, product image, influence, core technology, and quality. They are magnified for explanation into 22 issues (Table 2). (2) Finding the fuzzy front: integrating higher value of VOA from interpretive structural modeling (ISM) defines problem to be an issue as design guidelines. (3) Proposing innovative caring design direction: this is planning from fuzzy front to the present scenario using pictures of LEF (life style, ergonomics, and feature).

The principal of ISM is as follows: assign weights $w_{i}$ for the $i$ th element according to its relative position in the individual hierarchy. By summing the individuals, a collective score $w_{i j}$ can be assigned to each element, constructing the matrix $[A]$ to present the related relationship of each element (formula (7)):

$$
\begin{gathered}
{[A]=\sum_{j=1}^{n_{j}} w_{i j},} \\
{[A]=\left[\begin{array}{ccc}
w_{11} & \cdots & w_{i 1} \\
\vdots & \ddots & \vdots \\
w_{1 j} & \cdots & w_{i j}
\end{array}\right] .}
\end{gathered}
$$

Malone [42] showed that a matrix is termed the adjacency matrix of $D$ and is constructed by setting $a_{i j}=1$, wherever there is an $\operatorname{arc}$ in $D$ directed from element $s_{i}$ to element $s_{j}$, and by setting $a_{i j}=0$, elsewhere. Element $s_{j}$ is said to be 

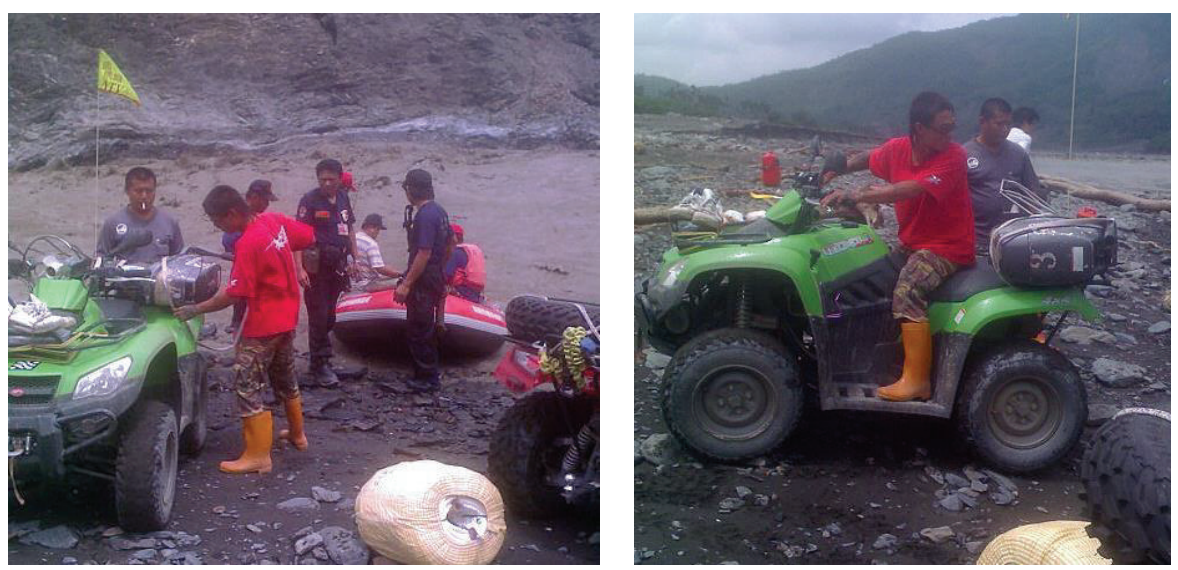

FIgURE 3: Morakot Typhoon, KYMCO Motorcycle Company sponsored ATV to transport materials into the disaster area [54].

reachable from element $s_{i}$ if a path can be traced on $D$ from $s_{i}$ to $s_{j}$. By convention, an element $s_{i}$ is said to be reachable from itself by a path of length 0 . The reachability matrix $M$ of a digraph is defined as a binary matrix in which the entries $m_{i j}$ are 1 if element $s_{j}$ is reachable from element $s_{i}$; otherwise $m_{i j}=0$. It can be shown that the reachability matrix can be obtained operationally from the adjacency matrix by adding the identity matrix and then raising the resulting matrix to successive powers until no new entries are obtained. That is,

$$
[M]=([A]+[I])^{n},
$$

where $n$ is determined such that

$$
([A]+[I])^{n-1}<([A]+[I])^{n}=([A]+[I])^{n+1} .
$$

2.4. Concreting Opportunities: Industrial Design Process. Product design courses are most commonly used to implement the thematic teaching mode; students accumulate design capabilities by the actual implementation of the product design process [51]. Design thinking and strategy can be divided into design, prototyping, and engineering stages. The design concept generated through interviews and data collection integration of content with each other: (1) design idea and (2) 3D modeling simulation.

\section{Identifying Opportunities: Research for Mountain Rescuing Products}

There are several conditions which have to be considered for distinguishing suitability; the rescue vehicle can be delivered from air or land for special landslides or normal mountain slides. The more useful delivery methods include helicopter from air, 4WD vehicle, ATV, and SUV from land.

3.1. Understanding Rescuing Situation. (1) Helicopter: the S70C, CH47, and B234 all belong to the Navy, Army Aviation, and Air Forces, which can provide higher altitude rescuing. Unfortunately, it is a dangerous vehicle for rescue tasks in mountainous jungles. Its propellers are easily entangled and wrapped in branches when it attempts landings in bad weather. Also, the flow cage and transmission power wires become harmful to rescue operators. (2) 4WD vehicles: the HMMWV (high mobility multipurpose wheeled vehicle) of the Army is the best off-road "Hummer" and is a well-known 4WD. Most other 4W drive vehicles are commandeered by civil search and rescue teams. (3) Mountain bike: this option is suitable for riding on mountainous road or in jungles, but it is difficult to carry injured patient. (4) ATV (allterrain vehicle): the ATV can overcome all road barriers. It is compact and flexible in moving on rough terrain and can carry rescuers and equipment into disaster areas for early rescuing operations such as site assessment, site security, controlling patient case, and immediate caring for patients with equipment for maintaining life.

\subsection{Comparing the Better Rescuing Product for Special Terrain.} Table 2 shows that because the helicopters own load capacity and speed characteristics are poor, the $4 \mathrm{~W}$ (four-wheel drive) vehicles then become the most commonly used for rescuing. To compare characteristics between $4 \mathrm{WD}$ vehicle and ATV, $4 \mathrm{WD}$ vehicles have more expenses, especially maintenance, and it is difficult to equip for unexpected conditions. Rescuers need to be able to quickly reach any disaster location. The ATV can drive in places where helicopters cannot land or $4 \mathrm{WD}$ vehicles cannot pass. Therefore, the ATV has the most excellent advantages of characteristics, good flexibility, being small in size, easily approaching the disaster location, being not affected by road conditions, the ability of driving in rivers, forests, or rugged steep terrains, good load capability (440 lb and can tow up to $1,100 \mathrm{lb}$ ), and being more efficient. Moreover, it can transfer its equipment rapidly for various tasks' requirements: water pump, rescue aid kit, adding trailers to transport supplies, carrying stretcher, and so forth.

The ATV (all-terrain vehicle) is famous for running on all terrains; each type could have 3, 4, or 6 wheels. The ATV is the most tactical and practical vehicle on some special terrains. Many practical cases for rescuing in foreign locales occasionally stay in Taiwan as an emergency stopgap (Figure 3). The superiority of the ATV for rescuing is preferentially taken 
TABLE 3: Rescue expert interviewees.

\begin{tabular}{lcccl}
\hline & & Interviewee & Date & Belonging unit \\
\hline & 1 & Dr. Chung & September 21, 2011 & ROC Disaster Medicine \\
& 2 & Member A & September 29, 2011 & ROC Rescue Corps \\
Semistructured interview & 3 & Mr. Liu & October 17, 2011 & Kaohsiung City Fire Department/Ishaan detachments \\
& 4 & Mr. Chen & October 17, 2011 & Kaohsiung City Fire Department/Jasiah detachments \\
& 5 & Mr. Xu & October 17, 2011 & Kaohsiung City Fire Department/Jasiah detachments \\
\hline
\end{tabular}

TABLE 4: Issues of interview for AHP.

\begin{tabular}{|c|c|c|}
\hline Number & Issues & Interview perspectives \\
\hline 1 & Crossing the harsh terrain & $\begin{array}{l}\text { (1) When rescuing people, drowning in sandbar, river, and (2) forest fires, industrial } \\
\text { roads, dirt roads, gravel, and grass. }\end{array}$ \\
\hline 2 & Supporting rescue & $\begin{array}{l}\text { (1) Support "general vehicles" or "fire trucks" to reach any place; (2) reach streams coast } \\
\text { of river to rescue drowning. }\end{array}$ \\
\hline 3 & Carrying subsistence equipment & $\begin{array}{l}\text { (1) Portable Oxygen supply, (2) capability of carrying equipment, (3) rescuers can } \\
\text { reduce excess physical exertion. }\end{array}$ \\
\hline 4 & Flexibility of ATV & $\begin{array}{l}\text { (1) Lightweight, (2) May across 1.5 1.8 meters road drop, (3) climbing ability is adapted } \\
\text { to the steep slope. }\end{array}$ \\
\hline 5 & Using of the rear frame & $\begin{array}{l}\text { (1) ATV's body gravity is too high, (2) Unsafe throttle control knob. (3) It is poor to use, } \\
\text { body is too light, cannot be well fixed. (4) Limited driving distance owing to finite } \\
\text { capacity of oil tank }\end{array}$ \\
\hline 6 & Need of a stretcher & (1) For carrying the injured from landslides terrain, (2) the patient cannot sit in the ATV. \\
\hline 7 & Having the shock effect & (1) Prevent the harsh shocking and (2) avoiding insult to injured patients. \\
\hline
\end{tabular}

by European countries and generally deployed in public and private rescue groups.

3.3. The Required Equipment for Rescuing. Dr. Chung from the ROC Disaster Medicine group said that "The most important thing for the rescue team in disaster is selfsufficiency." The main equipment for disaster is general surgery, orthopedics, neurosurgery, portable respirators, and oxygen suppliers. Ministry of Interior [52] formulated ambulance equipment must include the following: (1) general first aid box: thermometers, blood pressure monitors, disinfection equipment, dressing equipment, breathing tubes, syringes, emergency medicines, sterile gloves, and masks; (2) spinal board: mainly used in suspecting spinal trauma to fix the patients' spine; (3) oxygen kit: carrying a portable oxygen kit that needs a minimum capacity (about $400 \mathrm{~L}$ ), pressure gauges, flow regulator, high pressure hoses, and pneumatic forced oxygen and suction device; (4) oxygen supplier: divided into nasal oxygen tube, ordinary mask, nonrebreathing mask, and wake-up ball, respectively, used for different conditions; (5) fracture fixation: fixing patients' fracture position to reduce secondary injury from moving; (6) stretcher: conveying patients as a temporary bed to the hospital; (7) collars: protecting the cervical spine by keeping the cervical spine at a centered position in order to avoid second injury.

\section{Realizing Opportunities}

4.1. Extracting Constructs from Expert Interview. The interviews for caring disaster scenarios: five experienced rescue experts (see Table 3) were invited to interview. First, photos were prepared of ATVs and landslides to show each expert, discussing how to care, recognizing specific equipment, and the rescuers' challenges, in particular landslides and other harsh terrains: (1) the special needs of rescue equipment such as ropes and stretchers; (2) mentioning urgent patient needs to make for stable performance and ensure the safety of the patient; (3) the concerns of rescue staff avoiding danger and reducing burdens.

The ATV has been evaluated as being suitable for all terrains. Depending on expert interviews and evaluations in terms of being certified and suitable for landslides, Mr. Chen said that “The ATV's tire and suspension is suitable for driving on slopes, rough terrain and gravel riverbeds, and collapsed roads. Unfortunately, it cannot easily drive on normal asphalt and can easily be overturned." Chen suggested "improving the assembly of the spinal board on the rear frame of the ATV to reach a fast and stable usability."

Another advantage of the ATV is that it is convenient for rescuing. It usually coordinates with an ambulance, and its overroad capacity can easily lead to victims on special terrains. It can be equipped with an aid kit and a spinal board to convey sitting or standing patients, throwing guns and hanging ropes for distant victims, and fixed ropes for dependent injuries.

Table 4 shows that the main issues of ATV rescue are concluded from the expert interviews: (1) crossing the harsh terrain; (2) support rescue; (3) carrying subsistence equipment; (4) flexibility of ATV; (5) the use of the rear frame; (6) need of stretcher; (7) shocking resistance, structured in 
TABLE 5: Relative weight analysis of rescue experts.

\begin{tabular}{|c|c|c|c|c|c|}
\hline & Constructs factor & The weight between factors & Ranking of weight & C.I. & C.R. \\
\hline \multirow{7}{*}{$\begin{array}{l}\text { ATV rescue in } \\
\text { landslides }\end{array}$} & Crossing the harsh terrain & .085 & 5 & \multirow{7}{*}{.02} & \multirow{7}{*}{.016} \\
\hline & Special terrain rescue & .061 & 7 & & \\
\hline & Capability of carrying subsistence equipment & .209 & 3 & & \\
\hline & Flexibility of ATV & .124 & 4 & & \\
\hline & The use of the rear frame & .067 & 6 & & \\
\hline & Need of a stretcher & .228 & 1 & & \\
\hline & Having the shock effect & .227 & 2 & & \\
\hline
\end{tabular}

TABLE 6: The value of R.I.

\begin{tabular}{|c|c|c|c|c|c|c|c|c|c|c|c|c|c|c|c|}
\hline$N$ & 1 & 2 & 3 & 4 & 5 & 6 & 7 & 8 & 9 & 10 & 11 & 12 & 13 & 14 & 15 \\
\hline R.I. & 0 & 0 & .58 & .90 & 1.12 & 1.24 & 1.32 & 1.41 & 1.45 & 1.49 & 1.51 & 1.48 & 1.56 & 1.57 & 1.59 \\
\hline
\end{tabular}

two hierarchical levels, so that they can be operational by the abovementioned process AHP.

\subsection{Operating Analytic Hierarchy Process to Make Decision}

4.2.1. Hierarchical Structure Development of the AHP. As shown Table 4, seven issues have been selected as second level ideas to construct the hierarchical structure for AHP in the last section.

4.2.2. Weights Determination and Consistency Test. For the sake of more precise weights and consistency with the AHP method to measure key elements, each one is made between the various dimensions of the relative weight of the pairwise comparisons using AHP to measure key elements. They are made between the relative weights of questionnaire comparisons. If C.I. $\leq 0.1$, this indicates that the consistency of the matrix is satisfactory. If the comparison matrix does not have consistency, we can try to modify the hierarchy of the questionnaire or ask experts to rethink before ensuring the quality of the design.

The study invited twenty-two experts to join the pairwise comparison and nineteen experts achieved the standard of consistency ratio. In their reliable analysis test, the value of the consistency ratio is less than or equal to 0.1 , measuring the constructs of the problem in the same consistency; the reliability shows that it is a good questionnaire survey. Table 5 shows that the weights between the factors of ranking of weight, C.I. and C.R., the consistency index of all comparisons, are .02. The ranking and its weight: the first one "needs a stretcher (.228);" the second one is "shock resistance (.227);" the third one is capability of carrying subsistence equipment (.209). Finally, the calculating of C.R. = C.I./R.I., R.I. $=1.32$ (the factors are seven) (see Table 5), and, therefore, C.R. = $.02 / 1.24=.016$, indicates that the consistency of the matrix is satisfactory, and thus the consistency throughout the results can be accepted. It is realized that a stretcher is needed to convey patients with shock prevention and subsistence equipment in order to avoid hypoxia.

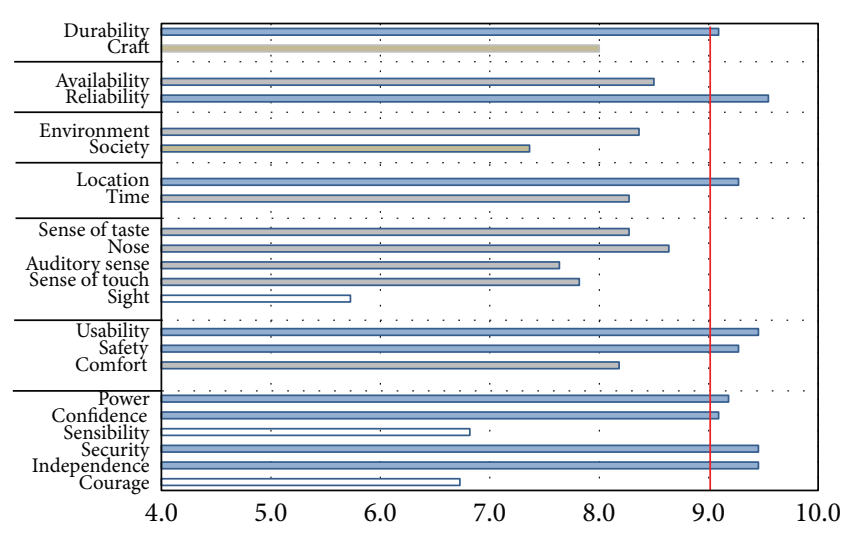

FIGURE 4: Value opportunity analysis of rescuing equipment.

\section{Conceptualizing Opportunities}

5.1. Operating Product Value Opportunity Analysis. The rescue stretcher on an ATV is used as a design target, using the operating product value opportunity analysis (VOA) (see Table 1) on further questionnaire surveys through the Internet. By selecting 10 segments, the Likert scale evaluates the survey. There are 22 questionnaires of VOA assessment evaluated by 11 examinees ( 6 males and 5 females) that have experienced suffering in natural disasters.

Figure 4 shows that survey average scores, with a selection of the higher items, were referenced for stretcher design. There are nine items that have a score higher than 9.00, which are "reliability" at 9.55, "ease of use (usability)" at 9.45, "sense of independence" at 9.45, "security" at 9.45, "safety" at 9.27, "location" at 9.27, "power" at 9.18, "durability" at 9.09, and "confidence" at 9.09. For finding the fuzzy front and constructing area of the main target and main problem the ISM is selected to decide their relationship.

5.2. Finding the Fuzzy Front by ISM. For finding the fuzzy front and verifying the relation of those five items, the ISM is selected to operate, depending on the method construct 
TABLE 7: Original matrix for ISM.

\begin{tabular}{|c|c|c|c|c|c|c|c|c|c|c|c|}
\hline \multirow{2}{*}{ Level } & \multirow{2}{*}{\multicolumn{2}{|c|}{ Description of number }} & \multicolumn{9}{|c|}{ Number } \\
\hline & & & 1 & 2 & 3 & 4 & 5 & 6 & 7 & 8 & 9 \\
\hline 2 & Reliability & 1 & 1 & 0 & 0 & 1 & 1 & 0 & 0 & 0 & 1 \\
\hline 3 & Ease of use & 2 & 0 & 1 & 1 & 0 & 0 & 0 & 0 & 0 & 0 \\
\hline 3 & Sense of independence & 3 & 0 & 0 & 1 & 0 & 0 & 1 & 0 & 1 & 0 \\
\hline 2 & Security & 4 & 1 & 0 & 0 & 1 & 1 & 0 & 1 & 0 & 1 \\
\hline 2 & Safety & 5 & 1 & 0 & 0 & 1 & 1 & 0 & 1 & 0 & 1 \\
\hline 3 & Location & 6 & 0 & 1 & 0 & 0 & 0 & 1 & 0 & 0 & 0 \\
\hline 2 & Power & 7 & 0 & 0 & 0 & 0 & 0 & 0 & 1 & 1 & 1 \\
\hline 1 & Confidence & 8 & 0 & 0 & 0 & 0 & 0 & 0 & 0 & 1 & 0 \\
\hline 2 & Durability & 9 & 1 & 0 & 0 & 1 & 1 & 0 & 0 & 0 & 1 \\
\hline
\end{tabular}

area, which is the main target or main problem. Processing for ISM the original matrix as in Table 7, the original matrix is checked for all items to find out each pair relation. The "1" and "0" describe "Yes" or "No" relations between rows and columns, for which decisions were decided by assessed persons. These are the three rescue experts of Table 3, who discussed together to decide their relations and follow a majority decision. (1) Constructing a correlation matrix is to conduct logical operations and analyze the resulting hierarchical structures from the most important VOA. To compare the relationships, a directional correlation matrix $[A]$ (see Table 7) is formed using the relationship $\left(a_{i j}\right)$ between one element and another. (2) Generating a reachability matrix: the reachability matrix $[R]$ is deducted from the incidence matrix $[A]$ if a Boolean $n$-multiple product of $[A]+[I]$ uniquely converges to $R$ for all integers $n>n_{0}$, where $n_{0}$ is an appropriate positive integer, $[I]$ is a Boolean unity matrix, and + is an addition in the Boolean sense [53]. Matrix $[R]$ represents all direct and indirect linkages between components. Relation transitivity is a basic assumption in ISM, representing the reachability matrix $[R]$ derived from matrix $[A]$, in which an entry $r_{i j}=1$ if component $j$ is reachable by $i$, although the path length may be one or more. "Reachability" in graph theory is the ability to move from one vertex in a directed graph to some other vertices. This is sufficient to find the connected components in the graph. (3) Generating a rearranged matrix: cluster elements affect one another in the output matrix of the reachability matrix. Figure 5 reveals that hierarchical interaction graph of the system has three clusters, namely, $\{8\},\{2,3,6\}$, and $\{1,4,5,7$, $9\}$, and the clustered components are integrated and treated as a single entity. (4) Illustrating the hierarchical relationships of elements: the hierarchy graph is then obtained by identifying a set of components in matrix $[R]$ that cannot reach or be reached by other components outside the set itself. The oriented links then connect the nodes from source to sink, based on the incidence matrix. Notably, the rounded rectangles indicate clusters within the retrieved group, in which the information flow forms a loop. In this step, the elements' hierarchical relationships are illustrated according to the rearranged matrix, providing decision makers with

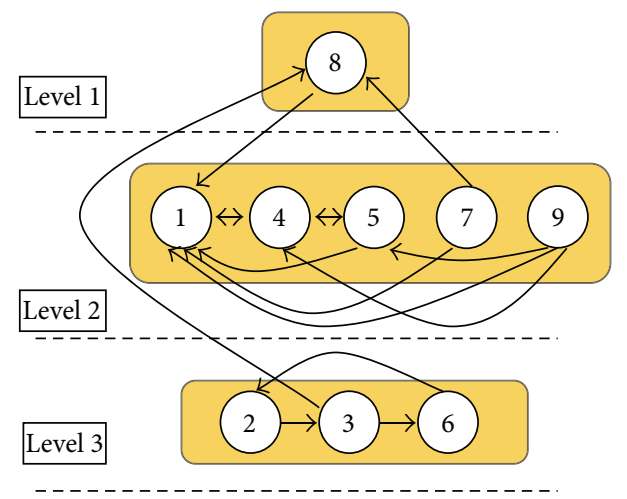

FIGURE 5: Hierarchical interaction graph of the system.

the procedures and hierarchical structures to use in the deconstruction of a problem. (5) Drawing the $D+R$ and $D-R$ element distribution graph: based upon the reachability matrix $[R]$, the user must add up the scores of the elements in each row to generate $D$ and the elements in each column to generate $R$. After this, calculate the values of $D+R$ and $D-R$ to generate a reachability matrix determinant and then demonstrate $D+R$ and $D-R$ on a binary scale to interpret both the problem and the target areas. This system can also be employed to analyze independent elements according to their hierarchical relationships. After the element level has been determined, draw the $D+R$ and $D-R$ element distribution graph to find out the main problem and main target (see Figure 6).

Conclusion of Figures 5 and 6 shows that the main target is level one $(\{8\})$ "confidence;" the main problems are level two $(\{2,3,6\})$ : "reliability," "security", and "safety" and level $3(\{1,4,5,7,9\})$ : "ease of use," "sense of independence," and "location." Figure 6 shows $D+R$ and $D-R$ element distribution graph that the rescue stretcher must achieve confidence for patient and driver, solving the problem of safety (level 2) and usability (level 3), ensuring a stretcher mechanism that is designed to sit on an ATV. It should comply with the principle of operation as being simple and 


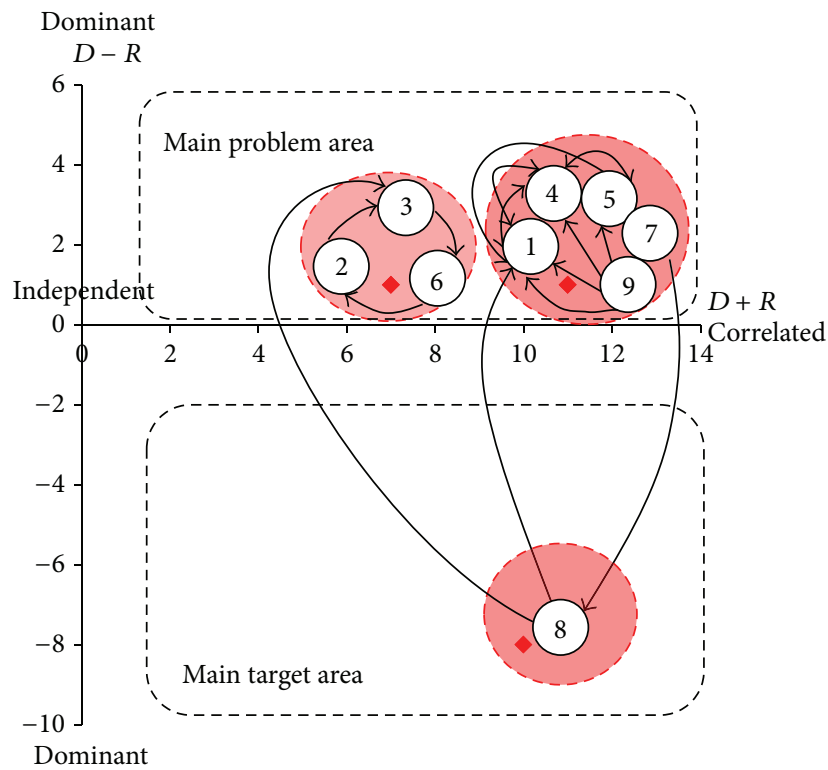

Figure 6: $D+R$ and $D-R$ element distribution graph.

easy as possible and be suitable to operate independently and will not cause user risk.

5.3. Proposing Innovative Caring Design Direction. The results of the ISM conclude that the fuzzy front for design purposes present a referenced product picture that can be a scenario for explaining the LEF (life style, ergonomics, and feature) mechanism (see Figure 7). The usability and reliable security of the model are essential elements of a rescue stretcher. This stretcher for an ATV is mainly used to retrieve an injured patient in harsh terrain during hurricanes on broken pavement. This study was sorted by the following three issues.

(1) Improving the stretcher design is as being safe and independent spinal board for retrieving.

(2) The stretcher must be allowed to fold and hang up to change utility and combine with the trunk and also allow for packaging subsistence equipment (portable oxygen machine) for an emergency (see Figure 7).

(3) The stretcher needs a resistant shocking mechanism in order to avoid another accident during the rescuing process; the creative solution of conveying Japanese noodles is a good referencing idea and solution to prevent this (Figure 7(a)).

\section{Concreting Opportunities: Practical Industrial Design Process}

Usually the existing ATV can enlarge its rear carrier to be fit for special purposes. It can also carry up to $440 \mathrm{lb}$, but the main problem is how to keep things safe and reliable for patients. It especially needs to use a stretcher and to avoid shaking when the ATV passes through rugged terrain. We can improve the stretcher as a foldable spinal board, referencing an existing mechanism of conveying noodles in Japan; it is a traditional vibrating prevention mechanism. Lastly, a portable oxygen device can produce oxygen from available water and prevent hypoxia.

6.1. The Main Design Idea. Figure 8 shows the main design of the multiple idea of a hang-up stretcher for conveying patients. Figure 9 shows that this stretcher is folded into a triangle where it can be stored with portable oxygen devices and other equipment. This equipment can be fixed by flexible ropes, which can help patients by preventing a release of the equipment. It is found that this design meets the demands of the flexibility and mobility required by ATV rescue. Figure 10 shows that it has a mechanism for avoiding vibration, which also needs reliable elastic ropes fixing the stretcher.

6.2. 3D Simulation Model. Figure 11 shows that the stretcher mechanism is simulated by $3 \mathrm{D}$ modeling software, displaying the location situation on the ATV. This stretcher has a tarp as a fixed cloth (see Figure 12); the frame can be folded into a triangle (see Figure 13). This design proposal is applicable, and simply needs further prototyping and engineering.

\section{Conclusion}

The complex structure of Taiwan's geology continues to produce seismic activity and natural disasters like earthquakes, typhoons, floods, surface deformation, and subsidence. It always results in loss of life and property when typhoons bring heavy rain, causing seasonal floods, landslides, and mudslides. In this study, we combined expert interviews and two types of decisions making the method research target and design be a product of innovative care design which will decrease black-box thinking.

Basically, the ATV has shown to be a more suitable vehicle for rescuing. After establishing this fact, it is simply finding out the possibilities of an ATV rescue, which was begun with the interviewing of five rescue experts to conclude seven important issues for searching design direction. This process used AHP to make direction decisions from certain priorities: the first five priority orders included "need of a stretcher," "shock resistance," "subsistence equipment," "flexibility of an ATV," and "crossing harsh terrain." It can be noted that a stretcher is required to rescue urgent patients, which will also prevent shock resistance that could hurt the patients and also protects against the hypoxia problem.

In order to confirm the value of this design direction, we have taken a questionnaire survey to select nine of the highest items from 7 categories, and we also processed ISM models to make a final design decision. In the end, the final product needs to reach the full confidence of the patients, to solve the safety and usability of the product. The final stretcher design is proposed to be suspended up in a suspension mechanism, to avoid swinging, fixed by a high coefficient elastic type rope. It is a designed foldable stretcher for rescuing patients in landslides or harsh terrain. 


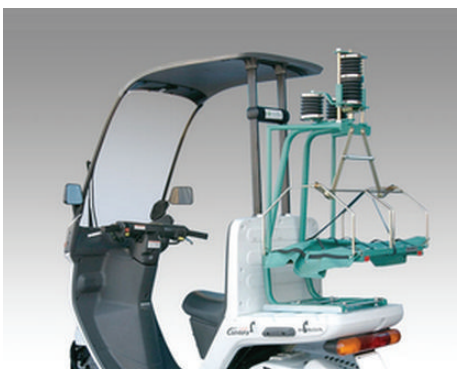

(a)

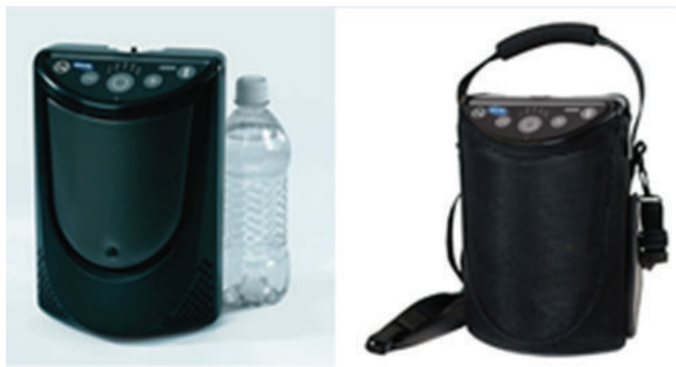

(b)

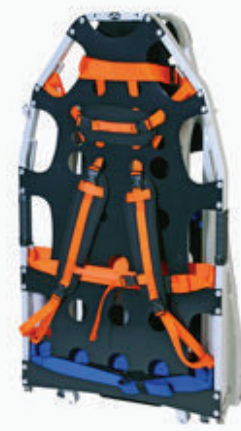

(c)

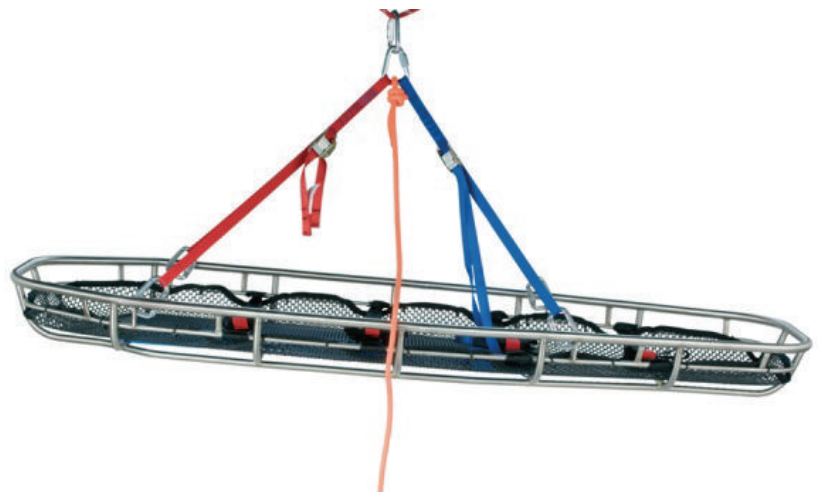

(d)

Figure 7: The related equipment for caring design: (a) delivery machine (http://item.rakuten.co.jp) [55]; (b) portable oxygen device (http://www.lakesidemedical.ca/Page7.html) [56]; (c) Alpine stretcher lite (http://www.sar-products.com/SAR_Alpine_Lite_Stretcher.html) [57]; (d) Rescue Stretcher Harness (http://safetec.eu) [58].

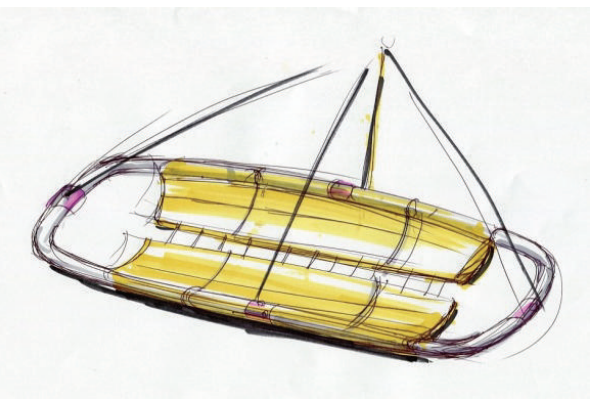

FIGURE 8: The stretcher can be hung up.

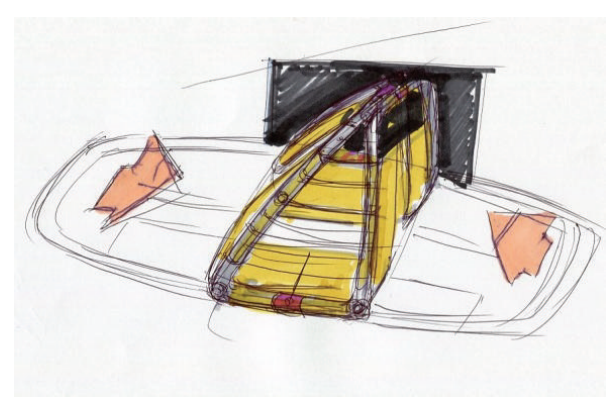

Figure 9: The stretcher can be folded into a triangular box.

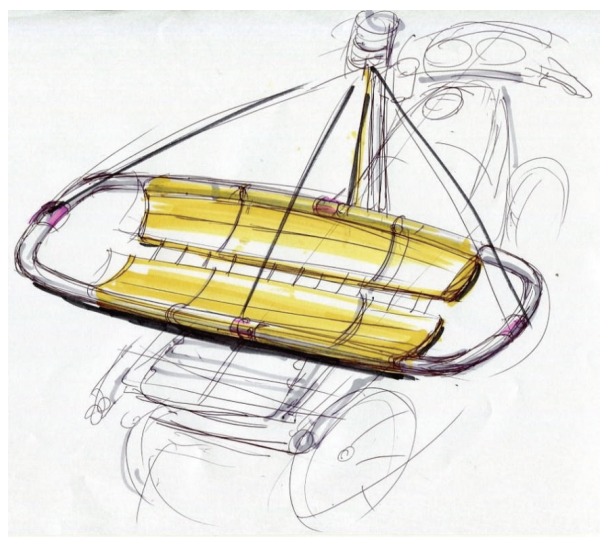

FIGURE 10: The stretcher can be set on the shock mechanism (the same as that which carries the Japanese noodle).

From this innovative design research method, we have designed a plan through the fuzzy direction to real detail by solidifying the design direction. The innovative care design was considered because it deals with society and the real needs for rescuing. This research is a good project for taking patients out of natural disasters. The government needs to have a broader care vision to solve these common situations, 


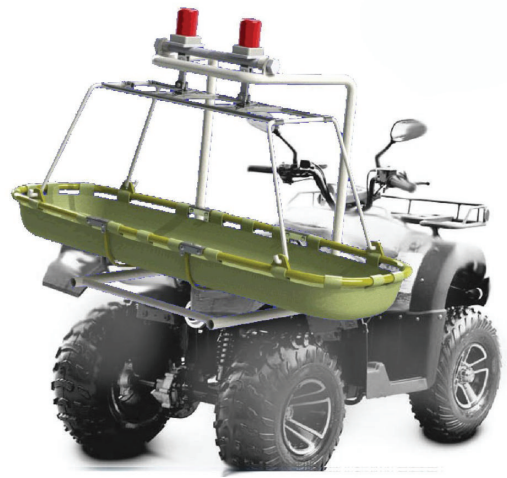

FIGURE 11: The proposal for rescuing a patient from an ATV carried on rough terrain.

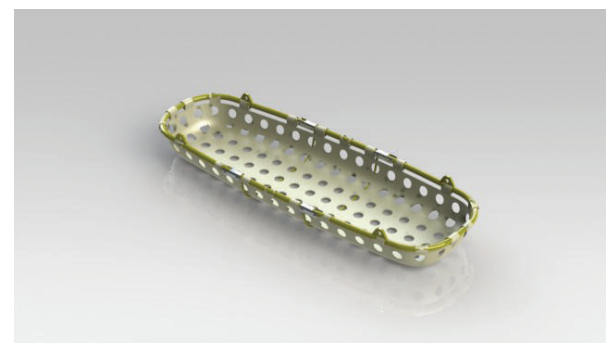

FIGURE 12: The stretcher design.

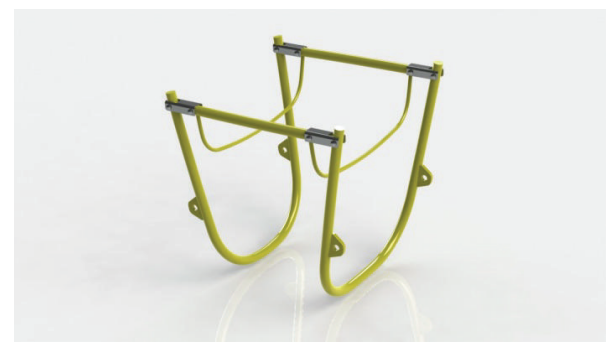

FIGURE 13: The triangular frame.

making it legal to own an ATV and run in main roads would be the first step.

\section{Conflict of Interests}

The author declares that there is no conflict of interests regarding the publication of this paper.

\section{References}

[1] S.-B. Yu, H.-Y. Chen, and L.-C. Kuo, "Velocity field of GPS stations in the Taiwan area," Tectonophysics, vol. 274, no. 1-3, pp. 41-59, 1997.

[2] K. Ulrich and S. Eppinger, Product Design and Development: New Product Design, Huatai Culture, Taipei, Taiwan, 2011.

[3] M.-C. Ho, M.-M. Lai, and Z.-F. Zhang, "Cooperation participatory design education-design research center in the professional design talent nurturing role," in Proceedings of the
Professional Design Talent Cultivation Symposium, pp. 183-187, National Yunlin Institute of Technology, 1997.

[4] N. Whiteley, Design for Society, Reaktion Book, London, UK, 2006.

[5] T. Conran (quoted in W. Kay), Battle for the High Street, Piatkus, London, UK, 1987.

[6] V. Papanek, Design for the Real World: Human Ecology and Social Change, D. Van Nostrand Reinhold Company, New York, NY, USA, 2nd edition, 1992.

[7] N. Noddings, Caring: A Feminine Approach to Ethics and Moral Education, University of California Press, Berkeley, Calif, USA, 1984.

[8] Care, 2013, http://oaadonline.oxfordlearnersdictionaries.com/ dictionary/care.

[9] Z.-H. Fang, Care Ethics and Education, Hung-Yeh Culture Enterprise, Taipei City, Taiwan, 2004.

[10] C. D. Batson, N. Ahmad, A. Lishner, and J. Tsang, "Empathy and altruism," in Handbook of Positive Psychology, C. R. Snyder and S. J. Lopez, Eds., pp. 485-498, Oxford University Press, Oxford, UK, 2005.

[11] N. Eisenberg, Q. Zhou, and S. Koller, "Brazilian adolescents' prosocial moral judgment and behavior: relations to sympathy, perspective taking, gender-role orientation, and demographic characteristics," Child Development, vol. 72, no. 2, pp. 518-534, 2001.

[12] M.-T. Wang, "Care for seniors tribe Healing toys explore design direction," Design Journal, vol. 17, no. 2, pp. 1-24, 2012.

[13] M.-T. Wang, The Evolution of the Concept of the Use of Teaching Topics Discussed - A Small Vacuum Cleaner Designed for Example, vol. 31, Kaohsiung Normal University, 2012.

[14] M.-T. Wang, "The starting concept of caring design and it's in between ethics' relationship," in Proceedings of the CID Annual Design Conference Proceeding; the Re-Evolution of Design Family, Tatung University, May 2014.

[15] H.-P. Chiu, C.-H. Liu, and R. K. Li, “The preliminary study of individuals with hearing impairment in using mobile phone's requirements and barriers on their activities of daily living," Journal of the Speech-Language-Hearing Association of Taiwan, vol. 23, pp. 1-20, 2009.

[16] J. Xu and H.-L. Zhang, "From 5-12 Wen-Chuan earthquake based on product innovation and design thinking to talk about emergency situations," Packaging Engineering, vol. 302, pp. 136$138,2009$.

[17] X.-Y. Cao and C.-W. Liu, "Caring convey emotions in interaction design research," National Taipei University of Science and Technology, vol. 442, pp. 65-84, 2011.

[18] T. L. Saaty, The Analytic Hierarchy Process, McGraw-Hill, New York, NY, USA, 1980.

[19] J. S. Dyer, "Remarks on the analytic hierarchy process," Management Science, vol. 36, no. 3, pp. 249-258, 1990.

[20] T. L. Saaty, "Axiomatic foundation of the analytic hierarchy process," Management Science, vol. 32, no. 7, pp. 841-855, 1986.

[21] J. S. Dyer, "Remarks on the analytic hierarchy process," Management Science, vol. 36, no. 3, pp. 249-275, 1990.

[22] S. L. Tung and S. L. Tang, "A comparison of the Saaty's AHP and modified AHP for right and left eigenvector inconsistency," European Journal of Operational Research, vol. 106, no. 1, pp. 123-128, 1998.

[23] P. T. Harker and L. G. Vargas, "The theory of ratio scale estimation: saaty's analytic hierarchy process," Management Science, vol. 33, no. 11, pp. 1383-1403, 1987. 
[24] Z. Xu, "Intuitionistic preference relations and their application in group decision making," Information Sciences, vol. 177, no. 11, pp. 2363-2379, 2007.

[25] S. K. Lee, Y. J. Yoon, and J. W. Kim, "A study on making a longterm improvement in the national energy efficiency and GHG control plans by the AHP approach," Energy Policy, vol. 35, no. 5, pp. 2862-2868, 2007.

[26] R. Ramanathan and L. S. Ganesh, "Using AHP for resource allocation problems," European Journal of Operational Research, vol. 80, no. 2, pp. 410-417, 1995.

[27] D.-R. Liu and Y.-Y. Shih, "Integrating AHP and data mining for product recommendation based on customer lifetime value," Information and Management, vol. 42, no. 3, pp. 387-400, 2005.

[28] R. J. Kuo, S. C. Chi, and S. S. Kao, "A decision support system for locating convenience store through fuzzy AHP," Computers and Industrial Engineering, vol. 37, no. 1, pp. 323-326, 1999.

[29] C.-C. Lin, W.-C. Wang, and W.-D. Yu, "Improving AHP for construction with an adaptive AHP approach $\left(\mathrm{A}^{3}\right)$," Automation in Construction, vol. 17, no. 2, pp. 180-187, 2008.

[30] J.-R. Chou, "A linguistic evaluation approach for universal design," Information Sciences, vol. 190, pp. 76-94, 2012.

[31] W.-L. Chen and Y.-M. Chiang, "A study on the customer requirement impact factors of baby walker based on orange technology," Kaohsiung Normal University, vol. 33, pp. 41-58, 2012.

[32] J. N. Warfield, An Assault on Complexity, Battelle Monograph Series, no. 3, Battelle Memorial Institute, Columbus, Ohio, USA, 1973.

[33] J. N. Warfield, Structuring Complex Systems, Battelle Monograph Series, no. 4, Battelle Memorial Institute, Columbus, Ohio, USA, 1974.

[34] J. N. Warfield, "Toward interpretation of complex structural models," IEEE Transactions on Systems, Man, and Cybernetics, vol. 4, no. 5, pp. 405-417, 1974.

[35] J. Warfield, Social Systems: Planning, Policy and Complexity, John Wiley and Sons, New York, NY, USA, 1976.

[36] J. N. Warfield, "Implication structures for system interconnection-matrices," IEEE Transactions on Systems, Man, and Cybernetics, vol. 6, no. 1, pp. 18-24, 1976.

[37] R. Attri, N. Dev, and V. Sharma, "Interpretive structural modelling (ISM) approach: an overview," Research Journal of Management Sciences, vol. 2, no. 2, pp. 3-8, 2013.

[38] A. P. Sage, Interpretive Structural Modelling: Methodology for Large-scale Systems, McGraw-Hill, New York, NY, USA, 1977.

[39] A. Agarwal, R. Shankar, and M. K. Tiwari, "Modeling agility of supply chain," Industrial Marketing Management, vol. 36, no. 4, pp. 443-457, 2007.

[40] F. Harary, R. Z. Norman, and D. Cartwright, Structural models: an introduction to the theory of directed graphs, John Wiley \& Sons, New York, NY, USA, 1965.

[41] M. N. Faisal, D. K. Banwet, and R. Shankar, "Supply chain risk mitigation: modeling the enablers," Business Process Management Journal, vol. 12, no. 4, pp. 535-552, 2006.

[42] D. W. Malone, "An introduction to the application of interpretive structural modeling," Proceedings of the IEEE, vol. 63, no. 3 , pp. 397-404, 1975.

[43] Y.-C. Lee, Y. H. Chao, and S.-B. Lin, "Structural approach to design user interface," Computers in Industry, vol. 61, no. 7, pp. 613-623, 2010.
[44] S.-W. Hsiao and E. Liu, "A structural component-based approach for designing product family," Computers in Industry, vol. 56, no. 1, pp. 13-28, 2005.

[45] S.-W. Hsiao, Y.-C. Ko, C.-H. Lo, and S.-H. Chen, "An ISM, DEI, and ANP based approach for product family development," Advanced Engineering Informatics, vol. 27, no. 1, pp. 131-148, 2013.

[46] S. Jharkharia and R. Shankar, "IT enablement of supply chains: modeling the enablers," International Journal of Productivity and Performance Management, vol. 53, no. 8, pp. 700-712, 2004.

[47] G. Coyle, Practical Strategy: Structured Tools and Techniques, Pearson Education, 2004.

[48] T. L. Satty and J. P. Bennet, "A theory of analytical hierarchies applied to political candidacy," Behavior Science, vol. 22, no. 4, pp. 237-245, 1977.

[49] J. Cagan and C. M. Vogel, Creating Breakthrough Products: Innovation from Product Planning to Program, FT Press, 2002.

[50] J. Cagan and C. M. Vogel, Creating Breakthrough Products: Revealing the Secrets That Drive Global Innovation, Pearson Education, 2013.

[51] H.-Y. Lin, "Deliberate practice applied in product design courses," Curriculum and Instruction Quarterly, vol. 14, no. 4, pp. 145-160, 2011.

[52] Ministry of Interior, "Rescue training and equipment introduced," April 2010, http://www.nfa.gov.tw/Show.aspx?MID=63 $\& \mathrm{UID}=66 \& \mathrm{PID}=63$.

[53] J. N. Warfield, A Science of Generic Design: Managing Complexity through System Design, Iowa State University Press, 1994.

[54] Morakot Typhoon, KYMCO Motorcycle Company sponsored ATV to transport materials into the disaster area, 2014, http:// forum.jorsindo.com/viewthread.php?tid=2141800\&highlight $=$.

[55] A former machine, http://item.rakuten.co.jp/teitofactory/nboxl1.

[56] Portable Oxygen sources, http://www.lakesidemedical.ca/Page7 .html.

[57] Alpine Stretcher Lite, 2014, http://www.sar-products.com/SAR Alpine_Lite_Stretcher.html.

[58] Rescue Stretcher Harness, April 2013, http://safetec.eu/components/com_virtuemart/shop_image/product/Rescue_Stretcher_ 4caf480c91bef.jpg. 


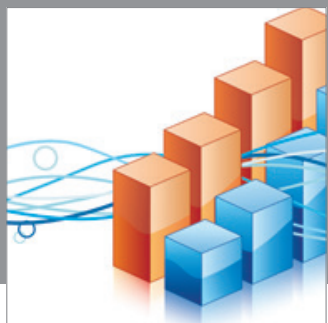

Advances in

Operations Research

mansans

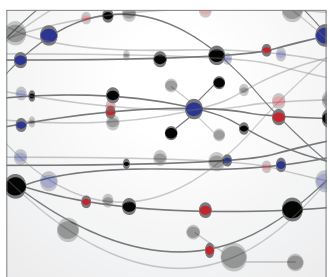

The Scientific World Journal
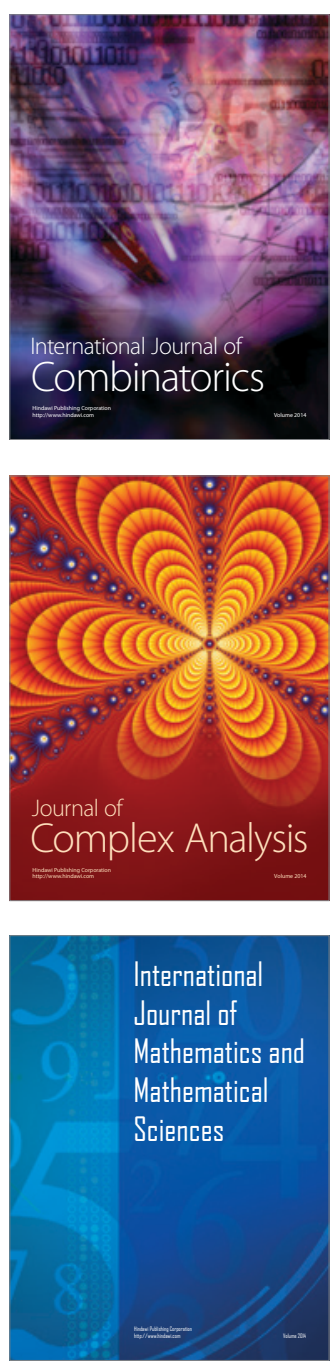
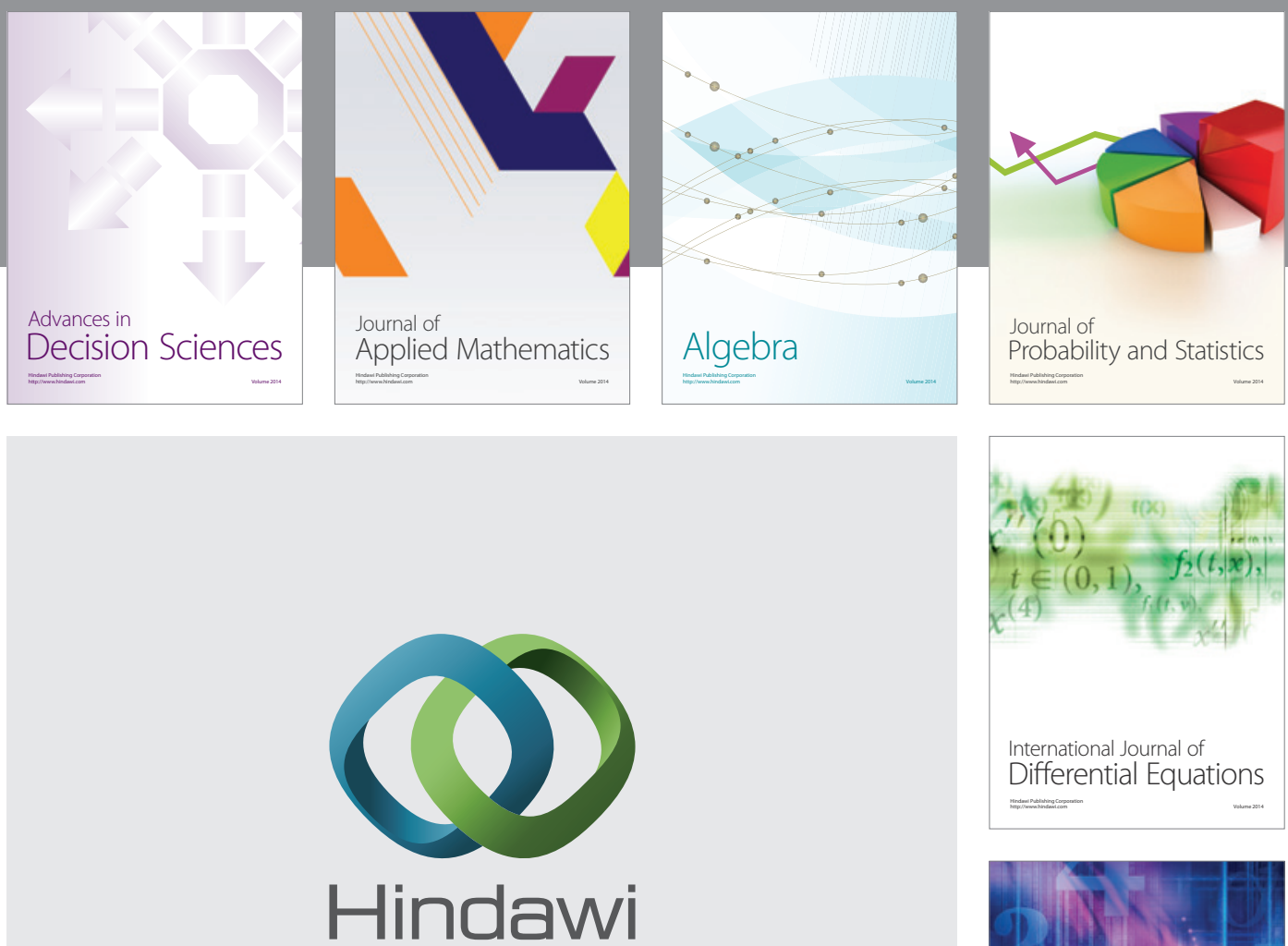

Submit your manuscripts at http://www.hindawi.com
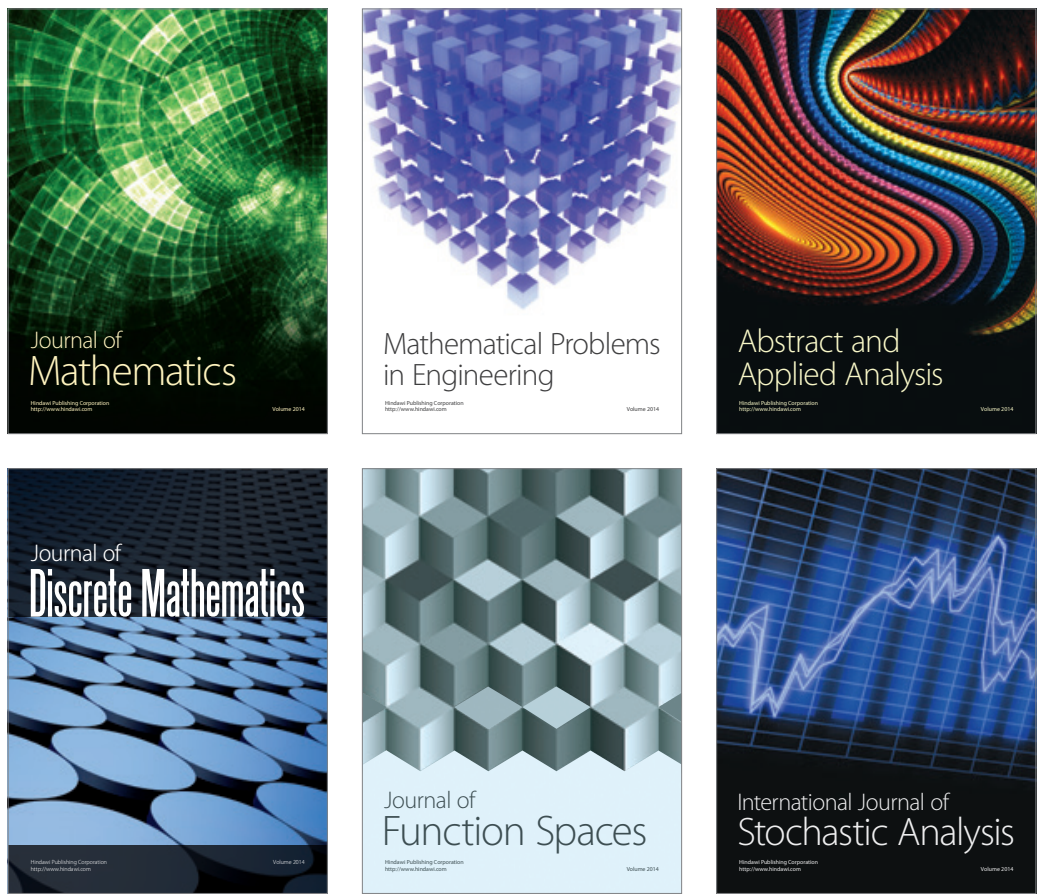

Journal of

Function Spaces

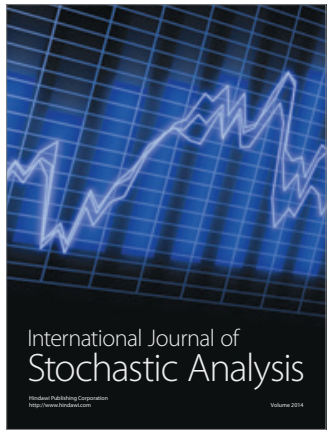

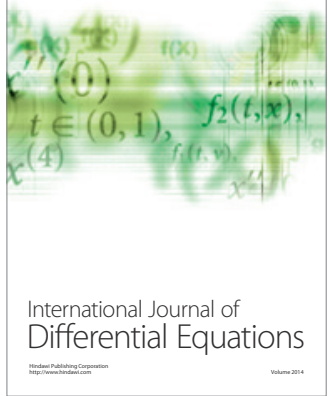
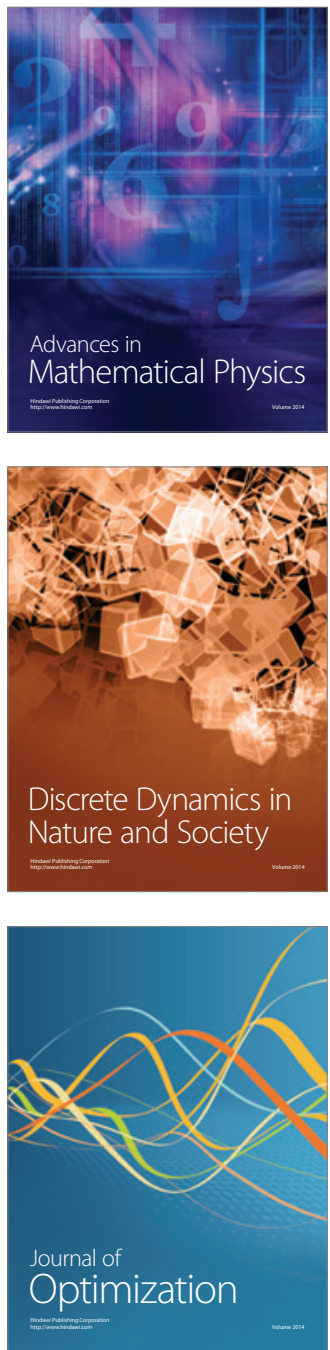